\title{
Collaboration or confrontation? Local and non- local actors in the Echigo-Tsumari Art Triennial ${ }^{*}$
}

SUSANNE KLIEN

Abstract

This article deals with selected contemporary art projects that have involved the collaboration of heterogeneous actors in the framework of the Echigo-Tsumari Art Triennial, which started in 2000 in southern Niigata Prefecture. Originally initiated as a revitalization plan to tackle depopulation and obsolescence in this vast rural area, the triennal has been envisaged and implemented by the Tokyo-based commercial gallery Art Front Gallery ( $A F G$ ) in cooperation with municipal and prefectural agencies. I will examine how the collaboration between local residents, non-local artist $(s)$, and volunteers has evolved in three projects that were all carried out in mountain villages. The first project entitled "Ubusuna no Ie" was initiated by a Tokyo-based editor and his staff for the 2006 festival, involving the restoration of an abandoned house, which now serves as a space to exhibit pottery. As a result of the project, the village women have started a restaurant in the house, which has been an enormous success, attracting hundreds of visitors per day in August 2009. The second project implemented in 2006 involved the cooperation of a British artist group called Grizedale Arts with the locals in a secluded marginal village called Töge in order to find ways to revitalize the village. The third ongoing artwork is concerned with promoting a brand of traditional Japanese paper (washi) by combining it with contemporary design and involves the cooperation between the vernacular washi production site and a Yokohama-based artist. Introducing a model to examine the development of kyōdō [literally: "working together"] by defining various stages of cooperation, the key issues I intend to explore are as follows: (1) What are the main factors that influence the implementation of the project, the intensity of cooperation, and its success? (2) What stages do we observe in the individual cases discussed here?

Keywords: collaboration; interaction; contemporary art; revitalization. 


\section{Introduction}

Facing each other, the 80-year-old local farmer's wife and the 20-yearold contemporary artist from Kanagawa Prefecture engage in an animated conversation - an odd couple at first sight, but the preparation of artworks to be installed in the abandoned local village school has brought together heterogeneous actors that would otherwise not meet, with surprising results in some cases (see Figure 2).

This paper examines selected conceptual art projects in a contemporary art festival in rural Japan; specifically I analyse the collaboration of local and non-local actors, what factors influenced the development of the cooperation, its extent, strengths and weaknesses, as well as structural features. After providing some information on the festival and its underlying principles, the theoretical notion of kyōdo or "collaboration" between heterogeneous actors as well as its interpretation in the triennial will be investigated. I will then discuss three cases in more detail before analysing the collaboration in each example, introducing a model that depicts the various stages that make up the collaborative process. I have chosen to examine examples of collaboration from this festival because it has brought together extremely heterogeneous actors in terms of generation, social background, geographical origin, and profession in its framework of contemporary art. The festival thus provides an ideal framework for examining experimental approaches to collaboration.

The central argument of the paper is that sustainable collaboration may be achieved despite continuing differences in priorities and values of stakeholders, if benefits for all sides are evident. It also shows that the role of intermediaries is essential during the entire process of collaborative interaction. Furthermore, contrary to previous definitions that envisaged contestation and networks as dichotomically conceived and relatively discrete categories (Giugni 1999; Tarrow 1994; Minkoff 1994), this study demonstrates that both elements of formal negotiation and informal exchange are coexistent, inherent, and significant parts of the collaborative process. This study draws on participant observation and extensive interviews with involved actors conducted in the Echigo-Tsumari region between 2007 and 2009.

The Echigo-Tsumari Art Triennial (henceforth: ETAT) ${ }^{1}$ in Tokamachi City in southern Niigata Prefecture has drawn attention as a catalyst for promoting interaction between people who have grown up in different socio-economic environments, and as a result subscribe to divergent values. Organized by the Tokyo-based commercial Art Front Gallery (AFG) directed by Fram Kitagawa, the international art festival has taken place four times since 2000 and has been financed by public (municipal and prefectural) as well as private funds. With more than 330 artists from 


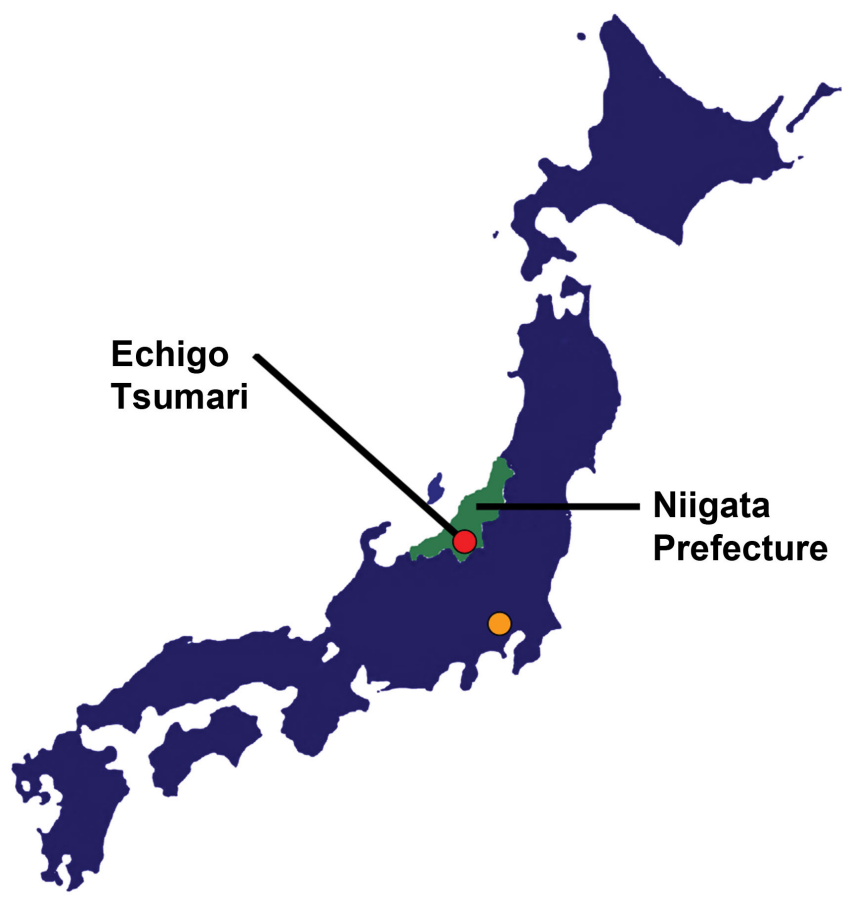

Figure 1. The location of the Echigo-Tsumari region.

45 countries, artworks are spread across 760 square kilometres of rugged mountains and terraced rice paddies; this landscape is referred to as the satoyama [traditional Japanese countryside] and is one of the catchphrases of the festival. AFG conceived the festival in cooperation with the prefectural and municipal governments as an instrument to revitalize the Echigo-Tsumari region, which has faced severe depopulation and ageing. The area corresponds to metropolitan Tokyo in size, but has only 70,000 inhabitants, with 30 per cent over 65 years old. According to statistical information provided by the Department of Civic Life at the Tokamachi Municipal Office, as of March 2008, the percentage of residents under 14 years amounted to only 12.5 per cent (Tokamachi City 2009).

The festival was part of the "New Niigata Riso Plan," which was envisaged by the prefectural revitalization agency with the aim of improving information policy on the region, attracting more short and long-term visitors to the region, and fostering residents' attachment to their native region by reinforcing the appeal of site-specific attractions such as nature, culture, and tradition. Envisaged as a means to achieve 
these aims, the festival contains the two principles of collaboration between heterogeneous actors $(k y \bar{o} d \bar{o})$ and "human beings as part of nature" (ningen wa shizen ni naihō sareru). As indicated in its name, the festival takes place every three years for approximately eighty days in the summer, but some events have also been organized outside festival times.

While the variety of artworks ranges from outdoor installations in rice paddies, ponds, abandoned schools or private houses - either vacant or still inhabited - to projects that focus on developing revitalization plans for a given village, with artists cooperating with the local residents, the idea of engagement with the community is salient in the triennial vision:

The basic point is that the artists are obliged to create works of art on other people's land ... But most of the artists are urban based, so local people are opposed to the idea of having some works in their rice fields and on their own land" $[\ldots$ t]o convince them to accept their idea, the artist has to learn the context of the region and the history, what is problematic in the area, and they try to show what satoyama [traditional Japanese countryside] means [to them] and what they find beautiful and interesting through their own works. In that process, the artist comes to understand the region itself and little by little the local people are convinced by the attitude of the artist and their way of working, and that is why the artist should be engaged with local people. (Kitagawa cited in Satterthwaite 22 July 2006)

Such encounters and cooperation between artists and locals have been facilitated by the engagement of so-called kohebitai [little snake squads] mostly young art student volunteers, but also including emerging artists, business people, and others; they functioned as the link between the resident community and non-local artists (Kuresawa 2008: 65). This supporters' group was formed in Tokyo in December 1999, half a year before the opening of the 2000 ETAT, without a formal organization or leader. Their name draws on the symbol mark of the ETAT, snakes. In 2000 , members of the little snake squad would trudge around the snowcovered region, visiting each house individually to explain about the Triennial (ETAT 2006: 8). Some of them received rather negative responses, but they facilitated communication between the elderly local population and urban youth and artists, with overwhelming scepticism being gradually converted into cautious optimism and, in some cases, support. The student volunteers were not only involved in the art projects per se, but also helped the locals by working in the rice fields, clearing snow or coping with the aftermaths of the Great Chūetsu Earthquake, which struck the area in 2004. 
In an interview, one Australian artist remembers that she was impressed by the close relationship between the senior locals and the kohebitai in charge of her project. Cooperation in preparing the artworks across generations, social milieu, and geographical origin is a prerequisite for the completion of the work, but what may be even more significant is the opportunity for social interaction and communication that emerges from the Triennial; without art there would be no occasion for the encounter or topic to talk about. According to the ETAT catalogue, an elderly farming woman told a kohebitai sitting next to her while preparing some artwork that she was somewhat embarrassed about her earth-stained hands from agricultural work, adding that she had faced difficult times in her life, but that she felt happy now. She recommended that the girl also gain experience by embracing hardship (ETAT 2007: 238). It is such encounters that hold potential for providing tacit, introvert, timid urban youth with opportunities to exchange experiences with people they would otherwise never meet. Needless to say, for the elderly locals, having an informal conversation with young people from the cities also provides a welcome break from their daily routine.

Surprisingly, none of the foreign artists whom I interviewed said in retrospect that they encountered major communication problems, despite their lack of Japanese language skills, adding that they were either accompanied by Japanese volunteer interpreters or communicated using their hands and feet. One Finnish artist even said that in her entire life,

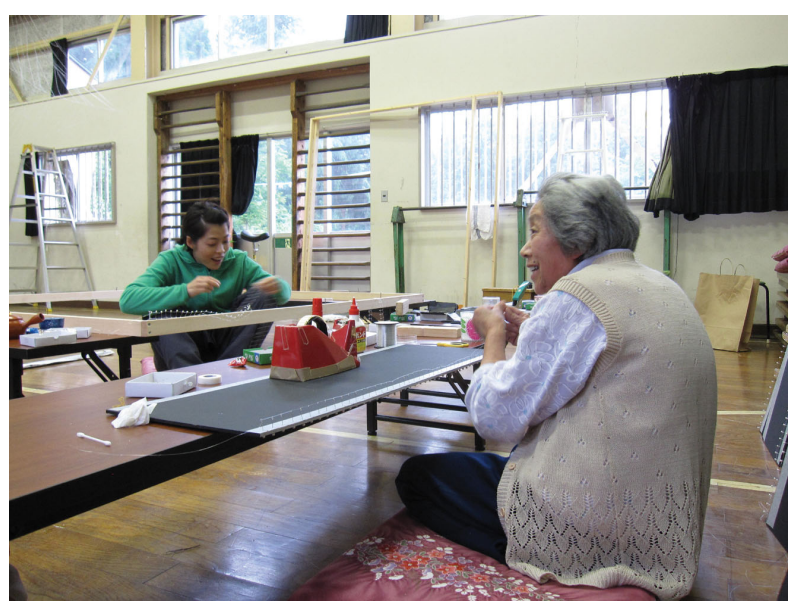

Figure 2. Collaborative preparation of artwork. The picture shows a young artist from Kanagawa Prefecture and a local volunteer in an abandoned primary school (Akakura village in Tōkamachi, June 2009).

Source: Picture taken by the author. 
she had never experienced such feeling of mutual understanding with locals beyond verbal communication. In fact, in many cases young Japanese volunteers from Tokyo indicated that they struggled with understanding the local dialect, especially in remote mountain villages.

In contrast to the positive examples discussed above, however, some residents were less positive, especially when well-established artists with tight schedules were involved, such as Ilya and Emilia Kabakov, who created the now famous installation "Tanada/The Rice Fields" in a private terraced rice paddy. The Kabakovs only came to the region twice and contacts with the rice field owner were limited; instead, the farmer interacted with gallery staff and kohebitai.

One resident of the village of Toge, which is well known for its picturesque paddy fields and has hosted several triennial projects, remarked about the festival:

If you ask me whether the event directly helps people in the community, I'm not sure. But as this community - like every other community in this area - is aging and has more and more elderly people, it's a good thing to have people from outside the community, such as England, Yokohama and Yamanashi, and to be able to talk with them. We can explain to them what the Toge community is like, and the event makes artists think about the community ... Even though the event may not be 100 percent positive for all the community, I hope the Triennial will be the starting point to make some progress. (Satterthwaite 22 July 2006)

In a similar vein, festival director Kitagawa emphasized that the ETAT does not aim to answer questions, but rather to raise questions, draw attention, and prompt people to move forward with, it is hoped, greater understanding and interest (Badtke-Berkow 2006: 15); in other words, AFG has pursued a process-oriented approach to revitalization. Kitagawa maintains that "[b]efore this event nobody came here, not even the children to visit their relatives. That is not true anymore. That is only one thing, but we have no other options. We believe that because people are coming back here and taking an interest in this place, because they are coming with their children, things will change" (Badtke-Berkow 2006: 15). The ETAT does not provide any concrete solutions to the structural problems that the Echigo-Tsumari region has grappled with; however, its catalogues, documentation material, and homepage ${ }^{2}$ indicate that it seeks to provide a forum that helps to correct the growing disparity between various groups in Japanese society by asking visitors and involved actors to rethink the accepted paradigms of contemporary life, such as the urban lifestyle focussed on convenience, effectiveness, 
and consumption, and re-emphasize the relations between man and nature, communication, and the importance of neglected ancient social practices, as (implicitly) evident in the subsequent statement by festival director Kitagawa: "Art can be used to express the distance between nature and humans, between civilization and humans, and between society and humans" (Kitagawa in ETAT [2007: 7]). This focus on immaterial issues does not only imply the conventional references to countryside as nostalgic furusato [home village] (see Robertson 1988), but holds great potential since it addresses revitalization issues at a level that is often neglected, as evident in Knight's cogent statement (1994: 642) that the "problems of the Japanese countryside were not simply material ones but also spiritual in nature."

Whereas the triennial puts equal weight on its aims of revitalization (if in varying nuances, as indicated above) and cooperation between heterogeneous partners, the aim of this paper is to focus primarily on the analysis of how collaboration evolved in selected cases rather than evaluate their success in terms of revitalization.

\section{Collaboration $(k y \bar{o} d \bar{o})$ : Theoretical definitions and issues}

\section{1. "Collaboration" in academic discourse}

Commonly translated as "partnership" or "collaboration," the Japanese term $k y \bar{o} \bar{d} \bar{o}$ [literally: "working together for a common purpose"] has become a ubiquitous catchphrase beyond the field of local governance over the past few years. Until a few years ago, the term did not feature on Japanese laptops or in dictionaries (Mori 2003: 14; Matsushita 2009: 3). According to the Oxford Advanced Learner's Dictionary of Current English, "collaboration" denotes "the act of working with another person or group of people to create or produce something" (Hornby 2000: 231); "partnership" is defined as "the state of being a partner in business" or "a relationship between two people, organisations, etc." (Hornby 2000: 923).

Japan saw early examples of town management based on kyōdō from the 1970s, with administration and citizens collaborating in Kobe in attempts to tackle pollution emissions resulting from intensive industrial activity in the area since the late 1950s (Healey 2009); however, the significance of the collaboration of various actors was acknowledged again in the wake of the disastrous earthquake that struck West Japan in January 1995 and claimed 6,434 casualties. The Japanese term clearly draws on the idea of co-production and collaboration defined by US political scientists Vincent A. Ostrom and Frances Pennell Bish in their (1977) work Comparing Urban Service Delivery Systems. However, the recent ubiquity of $k y \bar{o} d \bar{o}$ in Japan has resulted in the term being used in a 
variety of meanings in disciplines such as sociology, political science and economics. This has led to ambiguity of usage as to who should be collaborating with whom in what situation and to what end (Kanagawa 2008: 7). What is common to these definitions, however, is the equal partnership of various actors, with all of them being engaged to achieve some common purpose (Matsushita 2002: 36-37) and the continuation of this cooperation in the mid or long term (Sullivan and Skelcher 2002: 6). Previously, different forms of kyōdo have been distinguished, such as "network" and "partnership". According to Sullivan and Skelcher (2002: 5) as well as Klijn and Teisman (2000: 86), "network" constitutes a structure formed by informal relations and is characterized by trust and mutual benefit; it often includes features that exceed the borders of the structure and, in some cases, even goes beyond its purpose, being based on the relations between individuals. In contrast, "partnership" is a more complex term, which implies that people from various organizations work together for a common purpose over a longer period of time, which inevitably involves contestation and negotiation between individuals during a process of common decision-making. Furthermore, it implies that the cooperation of heterogeneous actors aims to produce benefits and added value that could not emerge from conventional structures (Mackintosh 1992). The notion of "collaborative advantage" (Huxham and Macdonald 1992: 50), that is, the creation of synergy between collaborating organizations, is understood as the emergence of something unusually creative, the achievement of some common aim, something that no organization could have produced on its own (Apostolakis 2004: 104).

In the background of this recent spread of the kyōdo term have been the changes of local and national governance due to administrative budget restrictions. A new form of partnership is the public-private partnership or PPP (kyōshi kyōdo $)$ in a wide range of areas; that is, a division of labour between government and the private sector on particular projects. Such partnerships have also become ubiquitous in local administration, the aim being to achieve greater local autonomy by entrusting tasks to the private sector wherever possible and, as a consequence, expand budget savings (Shiraishi and Niikawa 2008: 33).

During its initial 10-year-period, the ETAT also constituted such a cooperative venture between the state and private sectors: As mentioned above, the festival has been organized by a commercial art gallery in Tokyo, but emerged from a prefectural administrative plan and has been implemented with support from the municipal administration. In the cases discussed here, however, rather than the cooperation between municipal and prefectural levels of administration and the gallery, it is the encounters of local and non-local volunteers, artists and the gallery staff 
that will be at the centre of attention; in other words, I will focus on the collaborative endeavours of disparate social actors and the interpersonal dynamics that emerge in the process.

As regards the meaning of such cooperation between various sectors, mostly optimistic approaches have dominated, but Sullivan and Skelcher (2002: 36) also distinguish a pessimistic and a realistic view. Needless to say, optimists view $k y \bar{o} d \bar{o}$ as a constructive collaboration and empowerment of all stakeholders that results in an improvement of the system (Kanagawa 2008: 10), with involved actors subscribing to altruistic tenets. Pessimist views, on the other hand, assume that collaboration serves the respective interests of stakeholders in order to expand their power. Such views tend to be expressed by parts of the local community who are opposed to change for various reasons and/or see their own interests jeopardized. Realist approaches consider collaboration as a form of adaptation to a changing environment and contain elements of both altruism and self-centred power-driven behaviour.

\section{2. "Kyōdō" as defined in the ETAT}

Festival director Kitagawa embraces a clearly optimistic view of the collaborative partnership between heterogeneous players - i.e., non-local artists and the local community - the implication being that it serves to restructure and improve the world:

I sincerely hope that the Triennial will be a forum through which diverse people will interact with one another and live; that it will be a world where people work in the summer and read and learn in the winter, making winter and snow into our friends; that it will be a place where local people can take their own initiative; and a place where visitors will be invigorated. (Kitagawa, in ETAT 2007: 9)

In the framework of the ETAT rhetoric, however, non-material, emotional aspects in collaborative processes are emphasized, but despite the explicitly ideological content of the triennial, the success of collaboration ultimately hinges upon whether something emerges that is perceived positively by both sides - a "collaborative advantage" as it were, which is intricately entwined with very material issues. In the festival context, we find a strong emotional appeal apart from material benefits and an explicit political message: utilizing art as a means of regional revitalization in an attempt to fight the homogenizing effects of globalization, emphasize people-orientation and take measures against social disparities - a phenomenon that is exceptional in the Japanese contemporary art framework where art is mostly practiced "outside of society". The festi- 
val focus on collaboration and site-specificity - Kitagawa's emphasis on nature, human relationship, and returning to the neglected countryside - contains the message of reflecting on the present political, social, and economic system, be it at a national or global level: "What I think intuitively now is that both city and country are important to each other. It sounds trite, but I think that we live in an age that requires thinking about a division of roles, a sort of give and take relationship" (Kitagawa 2005: 27). While a majority of the collaboration in the ETAT framework has strong elements of a partnership as defined by Mackintosh (1992), the interactions of kohebitai with residents suggest distinct features of informal networks held together by mutual trust and a spirit of idealism that goes beyond formal structures of collaboration. Nevertheless, the sustainability of collaborative projects depends to a considerable extent on their economic success, as will be shown in the cases discussed in this paper.

\section{Introduction of a model of interactive development and discussion of three cases}

Previous research has favoured measurable material factors impacting goal-oriented cooperation and directed less attention to the non-material aspects of process-oriented collaboration, such as perceptions of involved actors. A notable exception is Katsumura and her colleagues (2008). While their qualitative study based on questionnaires distributed to the local communities in Echigo-Tsumari focussed mainly on social factors influencing local attitudes towards the triennial and shaping residents' willingness to collaborate in the art festival, my emphasis is on the interpersonal dynamics of the collaborative process itself.

Before introducing the individual projects and their processes of collaborative evolution, I will first present a model to illustrate stages of collaborative development and subsequently follow up by examining what stage collaboration has reached in each project. My ultimate aim is to contribute to the improvement of collaboration evaluation, that is, to optimize accounting for the impact of collaboration on the environment of the parties involved (see also Sullivan and Skelcher 2002; Powell 2003; Seko 2009), by analyzing the formation of the collaborative relationship. While I agree with previous studies that have corroborated the eminent significance of trust and equality of partners (Matsushita 2009: 17; Kanagawa 2008: 8; Sullivan and Skelcher 2002: 7), I claim that conflicts between the stakeholders do not necessarily affect collaboration negatively if they are communicated in a transparent manner; in fact, I argue that contestation is a part of collaboration and contributes essentially to sustainable collaborative arrangements. 
Table 1. From encounter to autonomy.

\begin{tabular}{lll}
\hline Stage of interaction & Extent of interaction & Feature of interaction \\
\hline 1 Encounter & Initial & Awareness of difference \\
2 Exchange & Cursory & Interest \\
3 Progress & Impetus & Affinity \\
4 Negotiation & In-depth & Conflict $\rightarrow$ Agreement \\
5 Collaboration $(k y \sigma d \sigma)$ & Enriching & Complementation \\
6 Autonomy & Decrease & Self-definition \\
\hline
\end{tabular}

Source: Klien (2009).

Slightly adapted from an earlier version which I used to demonstrate the salience of socio-political factors in collaborative development (Klien 2009), this model illustrates the evolution of the interaction from the first encounter between actors to friendship and collaboration, inevitably containing negotiation and conflict in the process. I apply it to the purpose of showing the variety of stages in interaction and the implications of human relations involved between stakeholders. Collaboration is characterized by what others have referred to as the "collaborative advantage" (Huxham and Macdonald 1992), "additionality" (Sullivan and Skelcher 2002) or "added value" (Camarinha-Matos and Afsamarnesh 2006), something that I prefer to call "complementation" or "enrichment" since in the triennial context, the non-material aspects outweigh the significance of material factors, even if the latter are undeniably important and affect the sustainability of collaborative endeavours. Autonomy constitutes the last stage in the process, meaning that locals have achieved a clear vision of self-definition and, as a result, elaborated plans and images of their own role in the future of their village and area. While many readers may take these for granted, the reality is often that residents have few opportunities to reflect on such issues. This is why external ideas and projects are eminently useful, even if locals eventually dismiss them as inadequate or irrelevant for their immediate context, as shown in the "Seven Samurai" project (see Section 3.3). Ultimately, successful collaboration is understood here as sustainable in the sense that all involved stakeholders perceive benefits in their participation. An earlier adaption of the model to different ETAT projects has shown the variety of perspectives and approaches involved in collaborative enterprises and their dependence on a number of socio-political and demographic factors such as village history, professional and age structure of residents, and the like. Beyond these insights, however, a question that remained unaccounted for was the role of intermediaries in the communicative process and their influence on collaboration between locals and non-locals. In other words: How did the collaboration start in the first place and what role did intermediaries between local residents and 
non-local stakeholders play in the beginning and throughout the collaboration?

Whereas the ETAT comprises innumerable artworks (referred to as projects here) that have entailed the cooperation between various actors - be it between artists and residents directly, between AFG staff and locals, administrative representatives of different levels, student and senior volunteers - I will focus on three examples here. These projects were implemented in different places, two of them in villages with a very limited number of residents. Kohebitai involvement only played a pivotal role in the third case.

As a general trend of the triennial development, the placement of artworks evolved from public places such as parks and near roads in 2000 to the centre of villages in 2003 and into private houses in 2006 (Kuresawa 2008: 68). This successive "intrusion" into private space has been followed up in 2009 by an emphasis on facilitating communication between locals and guests in the "Kurumaza Onigiri" project [Sitting in a circle to eat rice balls]. Here, locals would offer hand-made rice balls and mixed pickles in various villages and visitors would be called on to offer something in return, implying an opportunity for material as well as immaterial exchange in the process.

\subsection{The "Ubusuna no Ie" [Ubusuna House] project: Cooperation between villagers and non-locals - Success despite varying visions behind partnership?}

"We have had as many visitors as we would normally get in several decades!", residents of a village community said, unable to hide their surprise about the enormous number of visitors during the fifty summer days of the 2006 ETAT: A total of 22,711 guests were recorded, which made this project the most popular artwork in the entire third triennial (AFG 2006). The project entitled "Ubusuna no Ie" [Ubusuna House, literally The House of the Local Guardian Deity] was initiated by a Tokyo-based editor and his staff and involved the restoration of a farm house built in 1924, which now serves as a space to exhibit pottery. The restoration was funded to a great extent by Fukutake Soichiro, the owner of the large educational company Benesse, who purchased the house, and is also the general producer of the festival. The fact that Fukutake decided to acquire the stately but rundown house at the time symbolized the festival's commitment to promoting collaboration with the locals - this constitutes the first encounter between collaborative stakeholders, in this case representatives of the gallery, the project producer (the above-mentioned editor) and his staff, and villagers and local volunteers from outside the village. 
As a result of the relatively close collaboration, the cordial hospitality of the local women combined with the picturesque ambience of the refurbished house, the changing pottery objects by well-known artists on display, and the management of the house by the gallery and public relations work carried out by Art Front Gallery, have attracted numerous visitors from all over Japan.

The secluded village consists of only five households with 26 residents. Despite its tiny size, the population is relatively young, with four primary school children. This may be one of the reasons why - in contrast to other villages with larger populations - the overall atmosphere is outgoing and future-minded. Exchange between the residents and nonlocal stakeholders occurred during the initial stage of negotiation about purchase and restoration of the house and evolved into progress during the preparation of artworks for the 2006 triennial. As a result of constant exchange and interaction with non-locals, the village women have started a restaurant in the house, which has been an enormous success, attracting hundreds of visitors per day at the peak of the 2009 ETAT. The informal village leader, an energetic and charismatic mother in her late forties, recounts that the project has made villagers think about ways of revitalizing the village and aware of the importance of envisaging such measures beyond the village level - an important step towards taking the initiative in examining methods of promoting their village and area in tourism. Plans have even been discussed to open a bed and breakfast in a farmhouse in the village for travellers on a limited budget who seek to experience the local way of life.

The restaurant in the farmhouse offers guests "local" dishes such as a mountain plant hamburger menu with local ingredients, but the menu was in fact developed by the late editor and his staff, who are more familiar with urban expectations regarding taste and presentation. (See Supplementary photo 1 . The "local" mountain vegetable hamburger menu offered in the "Ubusuna House" [Source: Photo taken by author, 8 May 2008]: http://dx.doi.org/10.1515/cj.2010.010_supp-1.) The project producer aims to provide healthy and sophisticated food with the finest ingredients from the region and beyond, combining images of rustic nature with refined urban life; in contrast, locals admit to their own cooking containing large amounts of salt and artificial flavours. While the editor and his staff consulted locals when developing new menus and invited them to tastings - a stage corresponding to progress, with the parties involved exchanging their thoughts - the initiative of the entire revitalization plan has been mostly with the triennial people so far. Local reactions to the restaurant have been mixed: Whereas residents appreciate the revitalization potential of the project, very few locals frequent the restaurant, dismissing the representative "mountain vegetable ham- 

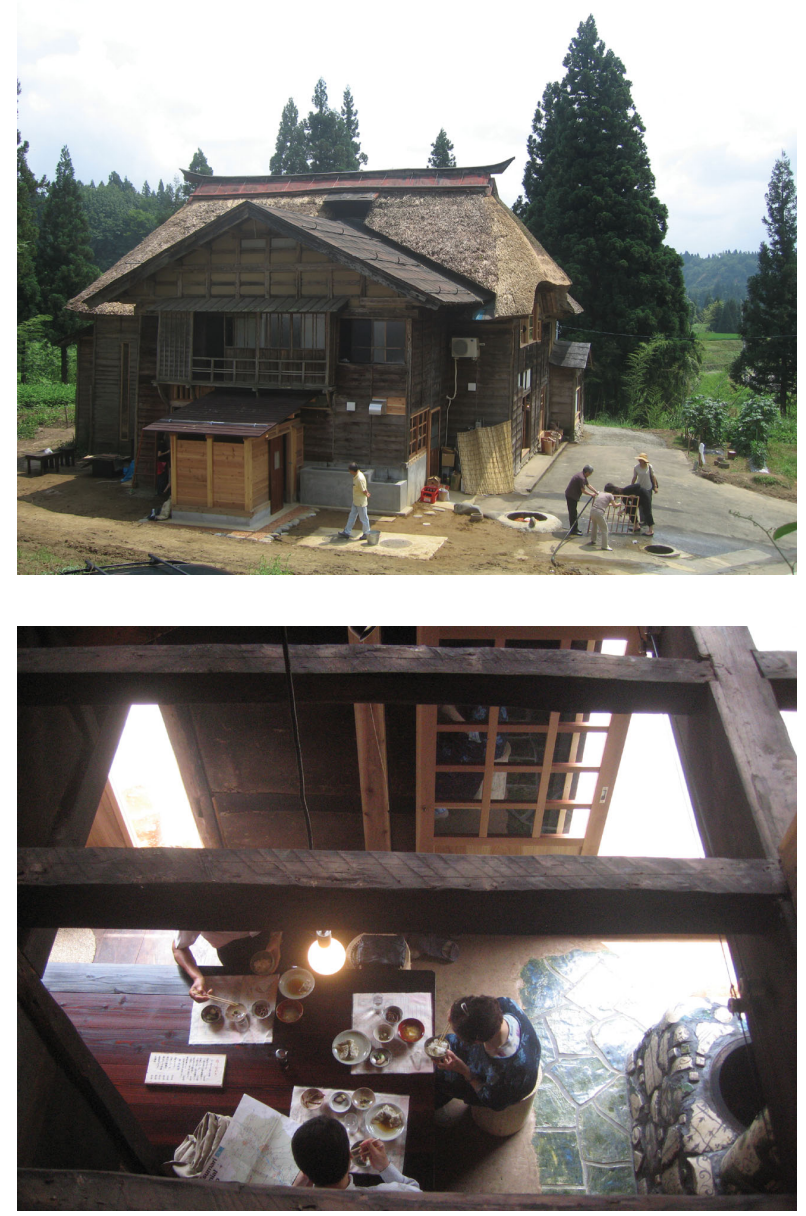

Figures 3 and 4. Refurbished farmhouse, outside and inside view, July 2006. Source: pictures taken by Markus Strobl.

burger menu" as too "stylish" (haikara), which once more testifies to the fact that dishes have been developed for the urban taste. The village leader concedes that locals and non-locals involved in the project have different priorities and values: For example, the editor liked to refer to the framework of universality, understanding the house as the seat of human civilization whereas architect Andō Kunihiro, who was in charge of the restoration, has conceived the house as a place of collaboration his vision is to revive the traditional values of solidarity and community. In his view, the refurbished farmhouse does not only symbolize a place 
where lost values such as partnership and cooperation are practiced, but it is also an accumulation of the past and at the same time contains suggestions for Japan's future (ETAT 2007: 25). According to Ando,

Studying the history of a traditional private house also can be viewed as an attempt to search for its future. During this process, the house turns into a place of kyōdo, and it becomes obvious that the continued existence of the house elicits kyōdo. This latter $k y \bar{o} d \bar{o}$ happens in families, in the region. It is the kyōdo of livestock, sericulture, the crop of the field, the vegetation of the satoyama. And now, the $k y \bar{o} d \bar{o}$ on a global scale has started. If one assumes that the creative force of these types of kyōdo has opened up the future of abandoned private houses, this is the meaning of the ETAT projects in such houses that have been left behind by their former inhabitants. (Matsudai 2006: 5)

In contrast, rather than engaging in such abstract reflections, the villagers involved in the project seem more concerned with immediate daily needs and the short- and mid-term perspective for their village. In an interview, one local resident pointed out to me that "both worlds are different and that the perspective of the gallery is too big." This salient difference in perspective has not impeded collaboration so far, but constitutes a potential source of conflict - and here we enter the stage of negotiation: for example, the local women involved in the project asked the owner of the house whether they could use it temporarily for community purposes, which was not accepted by Benesse; however, this divergence in perspectives has been alleviated by a female local volunteer from downtown Tōkamachi - a fervent ETAT supporter and advocate of promoting tourism in the region - who helped out almost daily at the restaurant and as a guide during peak festival times. Having both a pragmatic sense of what is feasible in reality and an understanding of the priorities of the festival organizers, she has made an essential contribution to the successful collaboration. Together with the locals she has helped to conceive and organize seasonal events throughout the year, such as the Doll Festival in March 2009, when guests could be dressed in kimonos, view antique hina dolls and enjoy seasonal delicacies. Despite the efforts of the go-between, an equal participation of both local and non-local actors in the consensus-building process is a sine qua non in order to maintain the project in the mid- and long-term. However, at present the local staff at the restaurant, in charge of the daily management, are still paid hourly wages while the urban staff controls finance, menu planning, and public relations. Given this division of labour and 
unequal distribution of financial resources, initiative and vision is not bound to emerge in local actors (Klien 2009; Mayo and Taylor 2001).

Despite these structural impediments, residents remark how much they have enjoyed encounters with people from outside their village and they also observe that as a result of such exchange and external validation, they have become aware of the attractions in their village and area. Residents and volunteers working in the farmhouse do not only serve the food and chat with guests, but they also guide visitors through the house, providing information on the displayed artworks and the region in general. These encounters constitute valuable opportunities for locals to see what visitors are interested in and what features of the local landscape and culture they find impressive. In other words, engaging in social interaction with visitors constitutes a break from routine. Taking all this into consideration, despite the structural adversities discussed above, signs of a sense of independence and initiative have evolved in this case, which means that stage five has been implemented (see Table 1) and the first steps towards stage six or autonomy have been taken.

Different values and priorities became salient at various stages on the part of the various involved parties, especially between the gallery staff, project producer, villagers, and volunteers. The lack of participation in the consensus-building process regarding long-term issues such as public relations, management, and finance, constitutes a potential source of conflict. Rather than a two-way process, the collaboration has been structured in a way that allows locals to formally air their opinions (e.g. at the tastings mentioned above), but not in a constructive way as to actually impact the structure of the partnership. So far, however, cooperation for the implementation of the project has been smooth in general, given the salient benefits and enrichment perceived by the involved actors: a successful art project from the perspective of the gallery staff, revitalization and social exchange for the villagers, external validation of the village, as well as the house and local culture for all stakeholders. The persistent efforts of a volunteer from outside the village who acted as an intermediary between local interests and the priorities of the nonlocal organizers have greatly contributed to the success of this collaborative endeavour. However, the cooperation here is characterized by an unbalanced labour division, since the parties involved are not equal and local participation in decision-making mostly pertains to the daily affairs of running the restaurant. Nevertheless, we need to concede that the project has managed to establish perspectives for the village by creating incentives for residents to reflect on ways of revitalization. After all, locals have conceived and organized events in the house with the intermediary - a first step towards autonomy. These signs of change are related to the relatively young demographic structure of the village and 
the strong presence of a charismatic village leader, which is not the case in the other examples, as well as to the efforts of the intermediary mentioned above. (See Supplementary photo 2. A local resident explains the history of the village to some visitors during the "Kurumaza Onigiri" Project in Shinzui, Tokamachi City [Source: Photo taken by author, 9 August 2009)]: http://dx.doi.org/10.1515/cj.2010.010_supp-2.)

\section{2. "Grizedale Seven Samurai": Envisaging ideas for revitalization}

The project entitled "Seven Samurai" entailed a group of seven British artists from the Lake District in rural Northern England, suggesting a range of ideas to revitalize the small mountain village of Toge, where they stayed for more than a month - much longer than most festival artists. The contemporary arts residency and commissioning agency Grizedale $\mathrm{Arts}^{3}$ has been involved in community revitalization projects based in the central Lake District. Rather than sitting art objects in some landscape, director Adam Sutherland states that the project was intended to "challenge the view of contemporary art as an arcane pursuit preserved for a self-serving urban clique" (Satterthwaite 22 July 2006). The artists' project proposal having been accepted for the 2006 festival, the team arrived in the summer, being accommodated in a vacant house in the village. Since the artists lived in the village for almost the entire duration of their stay in Japan, they were in close contact with the residents. Retrospectively, one artist remembers that in the beginning the group did not have the feeling that they were welcome, but with time and - in this case, too - thanks to the efforts of an intermediary, the Japanese wife of one of the artists, the group managed to establish a relationship of trust and friendship. One artist remembers that in the beginning he had the impression that the Toge residents were not quite sure what to make of the British group, but after a while they realized that the artists were not hostile, but in fact hoped to support them in various ways. Villagers brought fresh vegetables to the artists every day, which may be seen as matching stage two of our model (i. e., growing interest among collaborators). The emerging artists tried to do practical things such as develop a homepage in order to sell local produce, to offer artistic renditions of the landscape on a pay-per-view basis, with the proceeds going to the benefit of the community, or to create video pieces recording and documenting locals imitating bird voices from the area. Furthermore, the artists developed miniature farmhouses with thatched roofs in the typical regional style as souvenir objects to be sold at a well-known department store in Tokyo, with the proceeds from sales being assigned to the village. Many of the ideas for revitalizing Toge seemed promising and were discussed intensively with locals, corre- 
sponding to the stage of progress; the website developed by one group member that provided information on the village and local products abounded with dedication to detail. I ordered local unpolished genmai rice several times, with the products being delivered rapidly, but no invoice or cash-on-delivery system, as is customary. In other words, while the collaboration for the Internet delivery functioned smoothly with the British artists maintaining the homepage and notifying one of the villagers of the order, locals did not seem to be committed to actively selling their goods, something which may have to do with the fact that, historically, the agricultural cooperative was in charge of selling rice. However, at present the homepage has been closed and the souvenirs are not available any longer.

In fact, after the official end of the project, six villagers came to visit the group in England for one month in spring 2007; a Japanese café was organized where guests could eat wild vegetables and other typical culinary features from the Echigo region; and, what is more, some of the British have revisited Tōge since then. Thus, the project may be considered a success in so far as villagers welcomed the encounters with nonlocals and exchange between the involved actors continued even after the triennial ended. However, asked about their views of revitalization, Toge villagers point out that they are satisfied with their present lifestyle of farming and that they tend to see visitors - and tourism in general as an obstacle to their agricultural activities. One British artist observes that tourism was generally perceived negatively in that the photographers who came to take pictures of the terraced rice paddies in the village and its surroundings were seen as intruding upon local territory. Residents' disinterest in revitalization and the ETAT as such may have to do with the dominance of full-time farming as the main source of income in the village - rare even in Echigo-Tsumari nowadays with part-time farming having gained ground - as well as with the present demographic village structure of residents over 65 dominating (only one school-age child and no infants or babies). Against this background of salient disinterest in changing the status quo, one of the British artists remarks that it was rather challenging not to sound patronizing when making suggestions for revitalization when in fact locals were quite happy with their lives. Given these circumstances, it does not come as a surprise that some negotiation has taken place when locals and artists exchanged their ideas about branding local goods, but conflict has been missing here; as mentioned above, the efforts of the intermediary need also to be accounted for here.

The "Seven Samurai" project can be considered a success in terms of the intensive and positive social interaction that ensued between locals and non-locals and continued well until after the festival ended. Due to 
the basis of equality and trust achieved, stage 5 (collaboration) was reached, but not 6 (autonomy). The issue at stake here is that, ultimately, villagers do not perceive the need for change; thus, their commitment to collaboration has evolved to a greater extent from personal sympathy with their partners than belief in the meaningfulness of the collaboration as such. This is why the project has not managed to create a sustainable perspective for the village, even if it has turned out as an enriching experience for both parties involved in terms of social interaction and can be considered a success in terms of short-term revitalization.

\subsection{The "Isawa washi o sodateru" [Developing the Isawa Paper] project: Creating a brand}

This project is a collaboration between the local paper craftsman and a Yokohama-based light artist and graphic designer in a village with approximately 250 inhabitants called Inubushi. The aim of the project is the branding of local Isawa paper. Isawa refers to four villages including Inubushi, an area where handmade paper was traditionally produced from paper mulberry. The present cooperation goes back to 2006, when the craftsman and the artist produced washi postcards as their first common project together. The craftsman perceived it as a chance to expand his limited clientele, while the artist was in dire need of money as a festival artist with a project not related to washi - funds for emerging artists taking part in the festival being limited. The initial encounter between collaborators occurred when they were introduced to each other by a common acquaintance working for the Art Front Gallery. After discussions concerning their respective visions for promoting the paper - the exchange stage evolving into the progress stage - their first attempt at cooperation turned out as a success, with all postcards selling out rapidly, despite the "rather poor quality", as the artist observed in an interview. From the outset, the collaboration has been complemented by a young female contemporary art university graduate who, as a friend of the artist and former kohebitai volunteer in the ETAT, has made considerable efforts to help with the project and act as a go-between. Not only has she helped to mediate between the collaborators themselves, but she has also striven to engage the community. For example, she had the idea to start a newsletter containing updates about the paper project to be circulated to villagers regularly - a gesture of openness that has proven successful and valuable as a means of promoting understanding and cooperation among locals with regard to the project. (See Supplementary photo 3. View of washi installations by Nakamura Kei [Source: Photo taken by author, 19 August 2009]:

http://dx.doi.org/10.1515/cj.2010.010_supp-3.) 
The paper craftsman is in charge of manufacture; the artist has sought to develop new patterns. While the two men have joined forces for this project, their values and priorities differ considerably: the craftsman emphasizes the importance of communication, interpersonal relations, respect for ancient ways of paper production, and his foremost aim is to promote his handmade paper in the region; his collaborator develops the paper for a mostly urban, highly educated, and wealthy target group which appreciates sophisticated aesthetic design. He is primarily interested in producing paper patterns that go beyond the existing design and create a new context and ambiance, naturally questioning conventional technical and aesthetic aspects of paper production; the craftsman has manufactured the paper for functional purposes such as menus, sake labels or wallpaper. Locals tend to view the washi quite differently from the artist, since they consider it as a functional item for use in everyday life, though mostly in public places rather than in the private domain. The craftsman narrates that he suggested to the artist that a good way of raising villagers' awareness of their newly developed paper and washi in general would be to go to the sports ground everyday and engage in casual conversation, something that the artist dismissed as too timeconsuming and beyond his capabilities. The two worlds seem hard to unite, but their common aim is local and regional revitalization by reinventing the local paper and, in practice, the collaboration of the two men has seen considerable success in the 2009 ETAT, too: All products such as a paper fan or washi coasters sold out after a short time. What is also worth mentioning is the fact that most of the residents are not directly involved in the project, but the majority of villagers appreciate this success and hope for continued popularity of the paper - the increasing understanding and support of villagers is partly due to the above-mentioned newsletter.

Whereas the artist lives in Yokohama, he spends weekends and longer periods during the summer in the village. During their first washi postcard collaboration, the stakeholders experienced the initial stages of interaction: encounter, exchange, and progress. These phases have been interspersed with periods of in-depth negotiation, which was a result of the extreme diversity of the two collaborators, as outlined above. The volunteer and intermediary has elaborated in interviews that she has smoothened out numerous conflicts between the collaborators that resulted from their divergent values, but also their extremely different characters and ways of communicating.

Long-term participant observation has indicated that the non-local artist and the local craftsman have achieved a highly effective division of labour, the embodiment of stage five in the interaction model, or collaboration. Behind this lie rigorous efforts to negotiate a compromise: 
According to the artist, their divergent social upbringing, profession, and values have entailed differences in working style, priorities, and communication. After years of struggling to become accepted in the village community, the artist finally participated in the annual "naked summer festival" last year, where all village youth and men carry around omikoshi [portable shrines] in loincloths. The artist admitted that he had to down a substantial amount of liquor in order to summon up the courage to join. On the other hand, the craftsman remembers that he had difficulties in finding an acceptable balance between what he had learned from his master and cooperating with the artist on the project, but after a while managed to find a compromise with which he personally seems at ease. In other words, both actors have gone to great lengths to overcome initial divergences, and experienced ups and downs during their collaboration, in addition to being supported by an intermediary. While differences continue to exist, a division of labour acceptable to both sides has been achieved. Nevertheless, communication does not seem to occur on an equal level, which may be due to the age difference between the younger craftsman and the older artist, and to the fact that the latter is more familiar with the urban market for which the products are primarily developed. Furthermore, the artist has indicated several times that the task of the craftsman is to execute his orders as an artist.

What may be related to this lack of balance in power and an issue in terms of kyōdo development, is that the initiative continues to be predominantly driven by the artist. This is not surprising if one sees that only the name of the artist features in the project title, although the local paper name is mentioned. Once more, this project shows that responsibility and engagement go hand in hand: The artist remarks that if he did not come to the village regularly, the momentum for revitalization and branding would vanish gradually. Nevertheless, despite the difficulties arising out of the gap in values, social environment, and lifestyle, the fact that the two men have implemented the project together, with success, implies that a considerable amount of negotiation has taken place. While both the artist and the craftsman implicitly or explicitly indicate that they continue to perceive a fundamental gap between them, as they effectively live in different worlds, the collaboration has evolved and taken on a distinct shape, even if the exchange between partners is periodically interrupted due to the artist living and working in Yokohama.

The artist continues to be the driving force behind the entire project, with locals yet to take personal initiative. This, however, does not come as a surprise if one considers that the project was envisaged by the artist in the first place - even if it has involved collaboration with the local craftsman - and that the entire ETAT started as a top-down enterprise 
devised by a prefectural authority in cooperation with a commercial gallery. Given the evidence of collaborative advantage, the local sense of responsibility and participation may increase, but the hierarchical structures that have emerged between the craftsman and the artist are bound to sustain the unilateral, top-down approach that has emerged so far.

\section{Conclusion}

The three cases discussed in this paper suggest that due to the heterogeneity of actors involved in these projects, differences continue to be salient throughout the collaborative process. However, if the specific purpose of the partnership is precisely defined and widely perceived, and the benefit of collaboration - while interpreted individually - is still evident to all stakeholders, cooperation can be achieved despite the reality of different motives, values, and priorities of involved actors. The cases presented here have also shown the significant role of intermediaries throughout the various stages of interaction in collaborative projects. In all three cases, thanks to the efforts of a go-between (either a person from a different region of Japan or from a different locale in the region), differences of opinion were smoothed and communication between collaborators facilitated. The engagement of the go-betweens has contributed significantly to the enrichment of collaborators: in the first case, the conception and organization of events by the locals themselves (though adapted to the needs of non-local visitors); in the second case, social interaction and an incentive for the locals to rethink their local identity and ideas for revitalization. And in the third case, the intermediary has facilitated the problem-laden dialogue between the principal collaborators and has also engaged the community by means of her newsletter and visitors during workshops. Nevertheless, involvement of both partners in the consensus-building process and an agreement about the basic goals and ways of achieving these aims are prerequisite for the sustainability of collaborative revitalization projects. As shown in the "Seven Samurai" project, despite the successful social interaction achieved here, no longterm perspective emerges if local actors do not share the non-local assumptions about the need for revitalization and promotion of tourism a fact that is so self-evident that it tends to get frequently overlooked.

Generally, conflict - be it implicitly or explicitly expressed - is bound to feature in the collaboration process when actors approach one another and negotiate details of the cooperation. Examples discussed here have shown that collaboration often goes hand in hand with conflict, if stakeholders are convinced of and committed to the project. However, divergences of opinion do not necessarily affect the chances of sustainable collaboration. In both the pottery ("Ubusuna no Ie") and the paper 
("Isawa washi o sodateru") projects, stakeholders' interests conflicted at various points, but nevertheless a sustainable form of collaboration has been achieved. This is due to the evident benefit of collaboration to stakeholders as well as the sustained efforts of involved mediators.

All three cases illustrated the continuing awareness of difference among stakeholders from the very outset of the project, which did not necessarily imply conflict, if mediators managed to arbitrate between parties. If conflicts were fought out openly and resulted in compromises, this in fact contributed to the long-term feasibility of collaboration. Complementation in the project implementation, such as the running of the restaurant by locals, combined with the strategic planning by the gallery in the pottery case or the labour division in the paper branding case, adds to the sustainability of collaborative projects. In none of the three cases the last stage of autonomy has been achieved to date, since the projects themselves were based on external initiative, which resulted in the principal drive being in the hands of the non-local stakeholders.

One of the structural features of the ETAT is that before collaboration is initiated, (mostly) non-local artists would appear on site, hold explanatory meetings, and appeal to locals to cooperate in their project. This constellation qua nature contains some great challenges that could be seen as valuable incentives, but also be considered as inherent weaknesses that require great sensitivity, flexibility, and patience on the part of the external stakeholders to be overcome, since locals are not part and parcel of the conception process of the project from the very beginning and thus have no option to exert influence on the decision-making from the outset. The question of how the initiative could be passed on from non-locals to locals once a project has turned out as successful is still unresolved. This is why in spring 2008, a non-profit organization called "Echigo-Tsumari Satoyama Kyōdō Organization" was established to change this top-down unilateral framework and to strengthen the communication between locals and non-locals. It remains to be seen whether this organization can restructure existing hierarchies, reinforce local commitment, and thus facilitate the emergence of collaboration based on reciprocal initiative and engagement.

Last but not least, the three cases have shown the inherent coexistence of the categories of "partnership" and "network", as described by Sullivan and Skelcher (2002) as well as Klijn and Teisman (2000), that is, the entanglement of formal and informal elements in collaborative arrangements. All three projects have contained both processes of formal negotiation and informal frameworks of exchange. These categories are not mutually exclusive and discrete, as suggested by previous definitions, but have been shown to coexist and constitute prerequisites for the formation of sustainable collaborative structures. 
Susanne Klien (klien@dijtokyo.org) is a senior research fellow at the German Institute for Japanese Studies Tokyo (DIJ). She earned her $\mathrm{Ph} . \mathrm{D}$. in political science at Vienna University. Her research interests are rural revitalization, processes of tradition appropriation and agency, modern and contemporary debates about Japanese identity and the anthropology of happiness in contemporary rural Japan.

This paper was accepted for publication before Susanne Klien joined the German Institute for Japanese Studies Tokyo (DIJ).

\section{Notes}

* I would like to extend my cordial thanks to all involved project participants and representatives of the Art Front Gallery and of municipal and prefectural bodies who generously offered their time for questions and interviews. I am also thankful to Professor Agata Koichiro, Waseda University, and his graduate students for constructive feedback on earlier drafts of this paper, as well as to two anonymous reviewers for their valuable comments. Furthermore, I acknowledge generous financial support by the Japan Society for the Promotion of Science.

1. http://www.echigo-tsumari.jp

2. http://www.echigo-tsumari.jp/2009autumnen/outline/concept.html

3. http://www.grizedale.org

\section{References}

Apostolakis, Christos, 2004. Citywide and local strategic partnerships in urban regeneration: Can collaboration take things forward?. Politics 24 (2). 103-112.

AFG (Art Front Gallery). 2006. Kekka hokokushi [Report on results], Echigo-Tsumari Art Triennial Executive Committee (Ed.), Tokyo.

Badtke-Berkow, Joseph. 2006. There's an art to saving country life. The Japan Times Online. http://search.japantimes.co.jp/print/fa20060810a1.html (accessed 11 September 2006).

Camarinha-Matos, Luis M. \& Hamideh Afsamarnesh. 2006. Collaborative networks: Value creation in a knowledge society. In K. Wang, G. Kovacs, M. Wozny \& M. Fang (eds.), Knowledge enterprise: Intelligent strategies in product design, manufacturing and management (International Federation of Information Processing [IFIP]; 207), 26-40. Boston: Springer.

ETAT. 2007. Echigo-Tsumari art triennial 2006 catalogue. Tokyo: Gendai Kikakushitsu Publishers.

Giugni, Marco. 1999. How social movements matter: Past research, present problems, future developments. In Marco Giugni, Doug McAdam \& Charles Tilly (eds.), How social movements matter. Minneapolis: University of Minnesota Press.

Healey, Patsy. 2009. Developing neighbourhood management capacity in Kobe, Japan: Interactions between civil society and formal planning institutions. http:// www.unhabitat.org/downloads/docs/GRHS2009CaseStudyChapter04Kobe.pdf (accessed 24 March 2010).

Hornby, A. S. 2000. Oxford advanced learner's dictionary of current English. Oxford: Oxford University Press.

Huxham, Chris \& David Macdonald. 1992. Introducing collaborative advantage: Achieving inter-organizational effectiveness through meta-strategy. Management Decision 30. 50-56. 
Kanagawa, Koji. 2008. Kyodogata gabanansu to NPO - Igirisu no patonashippu seisaku o jirei toshite [Partnership-based governance and non-profit organizations the case of British partnership policy]. Kyoto: Kōyō Shobō.

Kitagawa, Fram. 2005. Kibō no bijutsu. Kyōdō no yume - Kitagawa Furamu no 40-nen 1965-2004 [The art of hope. The dream of collaboration - 40 years Kitagawa Fram 1965-2004]. Tokyo: Kadokawa Gakugei Shuppan.

Katsumura, Ayako, Ayumu Tanaka, Gōshu Yoshikawa, Izuru Nishimae, Kei Mizuno \& Shintarō Kobayashi. 2008. Jūmin ni yoru āto purojekuto no hyōka to sono shakaiteki yōin - Dai-ichi no Geijutsusai Tsumari Toriennāre o jirei toshite [Evaluation of art projects by local residents and social factors - the case of the first Echigo-Tsumari Art Triennial]. Bunka Keizaigaku 6 (1) (March). 64-77.

Klien, Susanne. 2009. Gendai ato ni yoru chiiki kasseika: Echigo-Tsumari Dai-ichi Geijutsusai (toriennāre) no jirei [Regional revitalization and contemporary art: The case of the Echigo-Tsumari Trienniale]. In Regional Development and Vitalization Meeting (ed.), Ima, motomerareru "chiikiryoku" to wa [What regional "power" is called for now?], 85-88. Chiiki Kassei Gakkai, Proceedings of First Research Meeting, Hōsei University, Tokyo, 11-12 July 2009.

Klijn, Erik-Hans \& Geerts R. Teisman. 2000. Governing public - private partnerships. In Stephen P. Osborne (ed.), Public-private partnerships: Theory and practice in international perspective. London: Routledge.

Knight, John. 1994. Rural revitalization in Japan: Spirit of the village and taste of the country. Asian Survey 34 (7). 634-646.

Kuresawa, Takemi. 2008. Paburikku ato o koete - Echigo Tsumari Toriennāre to Kitagawa Furamu no jūnen [Beyond public art - 10 years Echigo-Tsumari Trienniale and Kitagawa Fram]. In Takemi Kuresawa \& Sachiko Nanba (eds.), Biennāre no genzai [A present survey of bienniales], 45-74. Tokyo: Seikyusha.

Mackintosh, Maureen. 1992. Partnership: Issues of policy and negotiation. Local Economy 7 (3). 210-224.

Matsudai, Noubutai. 2006. Akiya purojekuto - ikitsuzukeru minka [Unoccupied Houses Project - Undead Minka], Echigo-Tsumari Art Triennial 2006, Tokyo: Art Front Gallery.

Matsushita, Keiichi. 2002. Atarashī kōkyō to jichitai [A new public and self-autonomy]. Tokyo: Shinzansha Shuppan.

Matsushita, Keiichi. 2009. Shimin kyōdō no kangaekata tsukurikata [Thinking about and envisaging civil collaboration]. Nara: Kizasu Shobō.

Mayo, Marjorie \& Marilyn Taylor. 2001. Partnerships and power in community regeneration. In Susan Balloch \& Marilyn Taylor (eds.), Partnership working, 39-56. Bristol: Policy Press.

Minkoff, Debra C. 1994. From service provision to institutional advocacy: The shifting legitimacy of organizational forms. Social Forces 72 (4). 943-969.

Mori, Kei. 2003. "Kyodo" no shiso to taisei [The philosophy and organization of collaboration]. Tokyo: Kōjin no Tomosha.

Ostrom, Vincent A. \& Frances Pennell Bish (eds.). 1977. Comparing urban service delivery system: Structure and performance. Beverley Hills, CA: Sage.

Powell, Martin. 2003. Review of Sullivan, Helen \& Chris Skelcher. 2002. Working across boundaries: collaboration in public services. Basingstoke \& New York: Palgrave. Health and Social Care in the Community 11 (2). 183-188.

Robertson, Jennifer. 1988. Furusato Japan: The culture and politics of nostalgia. Politics, Culture and Society 1 (4). 494-518.

Satterthwaite, Julian. 2006. Art amid the rice: "World's biggest" outdoor Triennal to revitalize Niigata? Daily Yomiuri Arts Weekend. 15, 22 July. 
Seko, Kazuho (ed.). 2009. Sanka to kyodo no dezain - NPO gyosei kigyo no yakuwari $o$ saiko suru [Designing partnership and collaboration - rethinking the role of NGOs, administration and companies]. Tokyo: Gakugei Shuppansha.

Shiraishi, Katsutaka \& Tatsuro Niikawa (eds.). 2008. Sanka to kyodo no chiiki kokyo seisaku kaihatsu shisutemu. [A system of developing regional public policy for participation and partnership]. Tokyo: Nihon Hyoronsha.

Sullivan, Helen \& Chris Skelcher. 2002. Working across boundaries: collaboration in public services. Basingstoke \& New York: Palgrave.

Tarrow, Sidney. 1994. Power in movement. Cambridge: Cambridge University Press.

Tokamachi City, Department of General Affairs, Section for Documentary Statistics [Tokamachi-shi Somuka Bunsho Tokei Gakari]. 2009. Tokei de miru Tokamachi [Statistics of Tokamachi], http://www.city.tokamachi.niigata.jp/files/1/10020667/ attach/2008-02.pdf, 41-58 (accessed 24 March 2010).

Yamaguchi, Michiaki (ed.). 2006. Kyodo to shimin katsudo no jitsumu (Atarasht jichi ga tsukuru chiiki shakai 2) [Practical challenges of partnership and civil activities (How new self-autonomy produces a regional society)]. Tokyo: Gyosei. 